\title{
Effect of Plant Revitalization Hormone and Foliar Fertilization on Growth and Yield of Boro Rice
}

\author{
M R Karim¹, M M Rashid1, M A Salam², M A Mazid², \\ M A Momin ${ }^{4}$ and M S Islam*
}

\begin{abstract}
Inherent soil fertility and application of exogenous fertilizer generally affect rice yield. Fertilization would be soil fertilization or foliar feeding through leaf area. Plant growth promoting substances also improve plant performance through modulation of its growth and yield. The study was conducted at BRAC Agricultural Research and Development Center (BARDC), Gazipur. The aim of the study was to find out the growth and yield of Boro rice as influenced by plant revitalization hormone (PRH) and liquid fertilizer Calsol and Magic Growth during dry season 2012-13 using randomized complete block design with three replications. Treatment consists of; $\mathrm{T}_{1}=$ Recommend fertilizer dose of NPKS and Zn (Control), $\mathrm{T}_{2}=\mathrm{T}_{1}+$ recommended $\mathrm{PRH}, \mathrm{T}_{3}=\mathrm{T}_{2}+$ half of the PRH, $\mathrm{T}_{4}=$ Half of doses of $\mathrm{T}_{1}+$ $\mathrm{PRH}, \mathrm{T}_{5}=\mathrm{PRH}, \mathrm{T}_{6}=$ Recommended fertilizer dose of NPK with three $\mathrm{N}$ top dressed along with Calsol, $\mathrm{T}_{7}=$ Recommended fertilizer dose of NPK with 1st and 3rd split of N application and along with three split of Calsol application, $\mathrm{T}_{8}=$ Recommended dose of liquid fertilizer Magic Growth. The effect of different treatment combinations of PRH and liquid fertilizer Calsol and Magic Growth showed significant difference $(\mathrm{p}<0.05)$ in panicle $\mathrm{m}^{-2}$, unfilled grain panicle $e^{-1}$, total grain panicle ${ }^{-1}$, and grain yield. However, none of the treatments out yielded the existing fertilizer application method. The application of $\mathrm{PRH}, \mathrm{Calsol}$ and Magic Growth significantly reduced rice yield than that obtained with recommended fertilizer dose.
\end{abstract}

Key words: Plant revitalization hormone, foliar feeding, Calsol, Magic Growth, yield

\section{INTRODUCTION}

Rice is the most important staple food in Asia, providing average $32 \%$ of total calorie uptake (Maclean et al., 2002). In Bangladesh, it covers about $80 \%$ of the total cropped area (BBS, 2008). In many Asian countries, population is still growing; therefore, demand for rice is expected to keep increasing in the coming decades (Pingali et al., 1997). At the current growth of population rice requirement increases dramatically and many nations are facing second-generation challenge of producing more rice at less cost in a deteriorating environment. To meet the current and future food requirements of increasing population and their rising dietary needs it is necessary to boost up crop yields (Gao et al., 2010). Therefore, yield boosting agronomic techniques such as; application of certain plant growth regulators, foliar feeding need due attention. Plant growth regulators are synthesized indigenously by plants; however, several studies show that plant can respond to exogenously applied growth ${ }^{1}$ Senior Agronomist, AFSP, BRAC; ${ }^{2}$ Advisor, AFSP, BRAC; ${ }^{3}$ Associate Director, Agriculture Programme, BRAC International; 4 SLO, Bangladesh Rice Research institute, Gazipur-1701; ${ }^{5}$ Programme Head, AFSP, BRAC, ${ }^{*}$ Corresponding author: sirajul.i@brac.net hormones. Exogenous application of plant growth regulators affects the endogenous hormonal pattern of the plant, either by supplementation of sub-optimal levels or by interaction with their synthesis, translocation or inactivation of existing hormone levels (Arshad and Frankenberger, 1993).

Plant hormones like Abscisic acid, Auxin, Cytokinine, Ethylene and Gibberillic acid etc are becoming popular to ensure efficient growth, production and for other necessary activities of rice plant. Talaat (2003) examined that, foliar spray of ascorbic acid significantly increased the macronutrient contents ie N, P and K. Salicylic acid played positive role in increasing the growth and yield of many cereals including wheat and maize at lower concentration (Khan et al., 2003). Remarkable accomplishments of plant hormone such as manipulating plant growth and crop yield have been actualized in recent years. These plant hormones are considered as yield boosting agronomic technique (Bakhsh et al., 2011). 
Foliar feeding also considered another yield boosting technique, which recently draws researcher attention for its less dependency on soil application fertilizer as well as increase. Soil fertilization is the most common method to supply essential nutrients to plants. On the other hand, foliar feeding is the practice of applying liquid fertilizers to plant leaves (Kovacevic, 2003). Silberbush (2002) reported that foliar fertilization is widely used practice to correct nutritional deficiencies in plants caused by improper supply of nutrients to roots. However, higher plants can also absorb mineral nutrients when applied as foliar sprays in appropriate concentrations.

Mineral nutrients are grouped into macro and micro elements (Michael A Grusak, 2001). In addition, from the plant essential points of view, all the nutrients are essential for plant growth and development (Fageria and Baligar, 2005). Camberato (2010) reported that if the micronutrient deficiencies do occur during the growing season, the most effective method for overcoming these deficiencies is through foliar fertilizer applications. Another report says that foliar fertilization is not a substitute for a programme based on soil applied fertilizers (Rehm et al., 1997).

Furthermore, it is an economical way of supplementing the plant's nutrients when they are in short supply or unavailable form in the soils and it has been shown that the efficiency of foliar application is three to five folds greater than soil-applied fertilizers, and can thus significantly reduce the amount of fertilizer usage (Jamal et al., 2006). Therefore, the term foliar feeding or application have been widely used in agriculture crop production especially in horticultural crop production but not yet popularized on cereal crops. Therefore, the study was carried out to gain knowledge and investigate the effect of plant revitalization hormone (PRH) and two liquid fertilizers Calsol and Magic Growth on growth and yield of Boro rice.

\section{MATERIALS AND METHODS}

The experiment was conducted at BRAC Agricultural Research and Development Centre, Gazipur during Boro season from December 2012 to April 2013 to evaluate the performance of PRH and liquid fertilizer: Calsol and Magic Growth. The soil of the experimental site was clay loamy with $\mathrm{pH} 6.72$ and had $2.15 \%$ organic matter content. $\mathrm{N}(0.187 \%)$ and $\mathrm{Zn}(1.096 \mu \mathrm{g} / \mathrm{g})$ was medium; K (0.130 meq/100 g) was low.
However, $\mathrm{P}(44.13 \mu \mathrm{g} / \mathrm{g})$ and $\mathrm{S}(39.14 \mu \mathrm{g} / \mathrm{g})$ were found above optimum level. The experiment was laid out in randomized complete block (RCB) design with three replications. The unit plot size was $3.8 \mathrm{~m} \times 2.8$ $\mathrm{m}$. The plot to plot distances were $70 \mathrm{~cm}$ and replication to replication were $80 \mathrm{~cm}$. The total numbers of treatments were 8 . The widely cultivated rice (Oryza sativa) variety BRRI dhan28 was used in the experiment. The mean air temperature during the crop cycle was minimum $\left(17.71^{\circ} \mathrm{C}\right)$ in January and maximum $\left(29.20^{\circ} \mathrm{C}\right)$ in April 2013 (Fig. 1).

Treatments: Treatments combination of recommended fertilizer, PRH, Calsol and Magic Growth described below:

$\mathrm{T}_{1}$ : Recommended fertilizer dose of NPKS and Zn (Control)

$\mathrm{T}_{2}$ : Recommended fertilizer dose of NPKSZn + recommended PRH

$\mathrm{T}_{3}$ : Recommended fertilizer dose of NPKSZn + half of the recommended PRH

$\mathrm{T}_{4}$ : Half of the recommended fertilizer dose of NPKSZn + recommended PRH

$\mathrm{T}_{5}: \quad$ PRH

$\mathrm{T}_{6}$ : Recommended fertilizer dose of NPK + (1st TDN (Nitrogen top dressed) + Calsol) + (2nd TDN + Calsol) + (3rd TDN + Calsol) 7 days before panicle initiation

$\mathrm{T}_{7}$ : Recommended fertilizer dose of NPK + (1st TDN + Calsol) + (2nd no TDN + Calsol) + (3rd TDN + Calsol) 7 days before panicle initiation

$\mathrm{T}_{8}$ : Recommended fertilizer + Magic Growth.

Recommended fertilizer application method. BRRI recommended fertilizer were applied. Nutrients at the rate of 103, 26, 60, 13, 4 kg ha-1 N, P, K, S and Zn were applied in the form of urea, TSP, MP, gypsum and zinc sulphate respectively. One third of urea, all the amount of TSP, two third MP, gypsum, zinc sulphate were applied as basal application and thoroughly incorporated with soil. Remaining urea was applied as top dressed during $20 \mathrm{DAT}$, maximum tillering stage (MTS) and before panicle initiation (PI) stage. The remaining MP was applied with urea at PI stage.

PRH application method. PRH was applied @ $200 \mathrm{ml}$ per 20 litre water for 0.10 ha $^{-1}$ every time. It was applied five times during the entire crop cycle. Before seed sowing in seed bed, seeds were soaked with PRH with 1-2 minutes @ $200 \mathrm{ml}$ per 20 liter water. Thereafter, when seedling height reached around two inches in seed bed in main field, it was applied before transplanting in concerned plot with the same rate. When crop established and plant height 
was 15 inches and finally it was applied before grain emergence period.

\section{Liquid fertilizer (Calsol) application} method. Calsol was applied along with urea top dress as per treatment. During each application it was applied @ $48 \mathrm{ml}$ per 15 litre water for 0.04 ha $^{-1}$ of land.

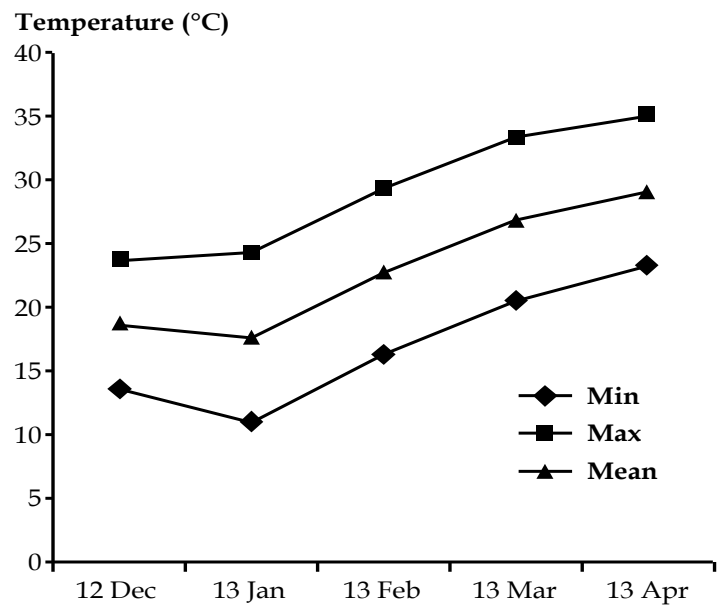

Fig 1. Maximum, minimum and mean air temperature during the crop cycle (December 2012-April 2013).

Liquid fertilizer (Magic Growth) application method. Herein, total TSP, MP (5 kg $\mathrm{ha}^{-1}$ less than recommended dose), gypsum, $\mathrm{ZnSO}_{4}$ were applied as basal application. First urea top dress was done on crop in an amount of one third of recommended dose at 15 days after transplanting (DAT) ie $33.33 \%$ of the total recommended dose. Second urea top dress was at 30 DAT using half of the first top dress ie $16.66 \%$ of the recommended dose. First spray of Magic Growth (MG) sprayed at 30 DAT (on the same date of 2nd urea broadcasted on crop) in afternoon at the rate of $32 \mathrm{ml}$ MG per 16 litre water, in addition with $200 \mathrm{~g}$ urea for $0.04 \mathrm{ha}^{-1}$ lands. Second spray of MG sprayed at 45 DAT in afternoon at the rate of $32 \mathrm{ml} \mathrm{MG}$ per 16 litre water $+200 \mathrm{~g}$ urea $+100 \mathrm{~g}$ MP for $0.04 \mathrm{ha}^{-1}$ lands. Third spray of MG sprayed at $60 \mathrm{DAT}$ in the afternoon at the rate of $32 \mathrm{ml} \mathrm{MG}$ per 16 litre water $+200 \mathrm{~g}$ urea $+100 \mathrm{~g} \mathrm{MP}$ for $0.04 \mathrm{ha}^{-1}$ lands. The fourth spray of MG sprayed at 75 DAT in the afternoon at the rate of $32 \mathrm{ml} \mathrm{MG}$ per 16 litre water $+300 \mathrm{~g}$ urea $+100 \mathrm{~g}$ MP for 0.04 ha $^{-1}$ lands.

Thirty-two-day-old seedlings were transplanted on 27 December 2012 maintaining two seedlings per hill and plant to plant and row to row distances were maintained $20 \mathrm{~cm}$. Gap filling was done with even aged seedlings within two weeks after transplanting. Mulching was done 25 days after transplanting (DAT) by hand. All experimental units were treated alike in terms of pest and disease management. Suntap was applied twice in entire growing season at 40 DAT and 83 DAT respectively at the rate $1.6 \mathrm{~kg} \mathrm{ha}^{-1}$. Perching was used as a biological control agent.

Five hills were selected after transplanting from each plot and data of plant height, tillers number from each plant at 20, 40, $60 \mathrm{DAT}$, flowering, and harvesting stage were measured and averaged. Panicle numbers and lengths were measured from three selected panicles, measured in $\mathrm{cm}$ and averaged. From selected panicles, filled and unfilled grains panicle-1 were counted and averaged. Thousand-grain weights were calculated from three unit samples of each plot and averaged. From each plot $8 \mathrm{~m}^{2}$ area was harvested and yield was converted to ton ha ${ }^{-1}$ at $14 \%$ moisture content. For partial budget analysis, fertilizer and other plant hormone, liquid fertilizer price, labour cost for fertilizer application process were recorded and calculated accordingly. Similarly income was also calculated based on market price of grain at that time. Recorded on different parameters were subjected to analysis of variance (ANOVA) by using MSTAT-C programme to examine the significant variation among different treatments. The treatment means were compared by DMRT at the 5\% level of significance.

\section{RESULTS AND DISCUSSION}

Plant height. Plant height increased gradually since 20 days after transplanting (DAT) to $50 \%$ flowering stage and reached peak at harvesting stage (Table 1). From 20 DAT to 60 DAT, no significant differences observed among the treatments and it varied significantly at 50\% flowering and harvesting stage across treatments. After transplanting to until 30 days average minimum temperature was about $11.09^{\circ} \mathrm{C}$. Therefore, plant height and canopy exposure were not developed properly as expected. To get favourable results from foliar feeding are most likely to occur when the total leaf area is large in agronomic crops (Foliar nutrition). However, Plant height reached peak and observed significantly higher in $\mathrm{T}_{3}$ treatment at both $50 \%$ flowering $(98 \mathrm{~cm})$ and harvesting stage $(99 \mathrm{~cm})$. On the other hand, at $50 \%$ flowering stage $\mathrm{T}_{3}$ also showed statistically similar to $\mathrm{T}_{1}(94 \mathrm{~cm}), \mathrm{T}_{2}(93 \mathrm{~cm})$ and $\mathrm{T}_{6}(93 \mathrm{~cm})$ treatments. The lowest plant height recorded in $\mathrm{T}_{5}(86 \mathrm{~cm})$ treatment. At harvesting stage, statistically identical plant height observed in $\mathrm{T}_{1}$ 
Table 1. Plant height of BRRI dhan28 as affected by PRH, Calsol and MG.

\begin{tabular}{lccccc}
\hline Treatment & \multicolumn{5}{c}{ Plant height (cm) } \\
\cline { 2 - 6 } & At 20 & At 40 & At 60 & $\begin{array}{c}\text { At 50\% } \\
\text { flowering }\end{array}$ & At hatvest \\
& DAT & DAT & DAT & \\
T1 & 17 & 29 & 52 & 94 & 98 \\
T2 & 15 & 26 & 49 & 93 & 97 \\
T3 & 17 & 29 & 51 & 98 & 99 \\
T4 & 15 & 23 & 47 & 87 & 94 \\
T5 & 17 & 18 & 46 & 86 & 88 \\
T6 & 16 & 26 & 48 & 93 & 99 \\
T7 & 15 & 27 & 49 & 90 & 95 \\
T8 & 15 & 25 & 49 & 87 & 92 \\
CV (\%) & 10.27 & 8.22 & 4.96 & 3.87 & 2.52 \\
LSD (0.05) & ns & ns & ns & 6.165 & 4.197 \\
\hline
\end{tabular}

$(98 \mathrm{~cm}), \mathrm{T}_{2}(97 \mathrm{~cm}), \mathrm{T}_{3}(99 \mathrm{~cm}), \mathrm{T}_{6}(99 \mathrm{~cm})$ and $\mathrm{T}_{7}$ $(95 \mathrm{~cm})$ treatments. Furthermore, the lowest plant height was observed in $\mathrm{T}_{5}(88 \mathrm{~cm})$ treatment where no chemical fertilizer were used except PRH. From statistical point of view, $T_{5}$ is identical with $T_{8}(92 \mathrm{~cm})$. Chowdappa (2013) reported that, rice plant height increase compared to NPK treatment using plant hormone Trichoderma spp. inoculated rice and also using other plant hormones. But our results are not consistent with this report, as we use different plant hormone and soil of experiment site was enriched with organic matter and other macro and micronutrients.

Tillers number. Number of tillers $\mathrm{m}^{-2}$ as affected by different treatment combinations of PRH and liquid fertilizer showed nonsignificant up to 60 DAT (Table 2). Maximum tiller production was observed at $60 \mathrm{DAT}$.

Table 2. Number of tillers of BRRI dhan 28 as affected by PRH, Calsol and MG.

\begin{tabular}{lccccc}
\hline Treatment & \multicolumn{5}{c}{ Tillers number m-2 } \\
\cline { 2 - 6 } & At 20 & At 40 & At 60 & At 50\% & At hatvest \\
& DAT & DAT & DAT & flowering & \\
T1 & 47 & 144 & 493 & 402 & 353 \\
T2 & 43 & 113 & 440 & 386 & 344 \\
T3 & 37 & 131 & 424 & 362 & 331 \\
T4 & 45 & 120 & 451 & 380 & 358 \\
T5 & 43 & 124 & 378 & 318 & 285 \\
T6 & 43 & 120 & 436 & 433 & 366 \\
T7 & 38 & 111 & 453 & 367 & 331 \\
T8 & 43 & 100 & 407 & 387 & 351 \\
CV (\%) & 17.69 & 12.18 & 12.24 & 8.35 & 7.57 \\
LSD(0.05) & ns & ns & ns & 55.46 & 45.05 \\
\hline
\end{tabular}

Thereafter, tiller production started to decrease and showed significant difference among treatments. $T_{6}$ (433) treatment produced the highest tiller number among treatments at $50 \%$ flowering stage and observed statistically identical with $\mathrm{T}_{1}$ (402), $\mathrm{T}_{2}$ (386), $\mathrm{T}_{4}$ (380), and $\mathrm{T}_{8}$ (387) whereas, $\mathrm{T}_{5}$ (318) ranked the lowest number tiller. With this consequence, during harvest, $\mathrm{T}_{6}$ (366) had the position of producing the highest number of tiller among treatments while $\mathrm{T}_{1}$ (353), $\mathrm{T}_{2}$ (344), $\mathrm{T}_{3}$ (331), $\mathrm{T}_{4}$ (358), $\mathrm{T}_{7}$ (331) and $T_{8}$ (351) showed statistically similar with each other. The lowest tiller production found in $T_{5}$ (285) treatment. Tiller production drastically decreased in all treatments except $\mathrm{T}_{6}$ from 60 DAT to $50 \%$ flowering stage. It might be due to Calsol application along with all the three $\mathrm{N}$ top dresses. This might help to increase the productivity of tillers. Another report also showed that, tiller production did not significantly differ using 100 ppm and 200 ppm NAA plant hormone (Adam et al., 2011).

Phenological parameters. Different treatment combination did not significantly affect the days to 1st flowering initiation (Table 3). On the other hand, they showed significant both at 50\% flowering and in total growth duration. Fifty percent flowering comes earlier at 122 days in $\mathrm{T}_{1}, \mathrm{~T}_{3}$ and $\mathrm{T}_{5}$ combinations followed by $\mathrm{T}_{2}, \mathrm{~T}_{4}$, $\mathrm{T}_{6}$ and $\mathrm{T}_{7}$ combinations with 123 days. Treatment 8 comes at 124 days. Total growth duration comes earlier at 139 days in both $\mathrm{T}_{3}$ and $\mathrm{T}_{5}$ followed by $\mathrm{T}_{4}$ with 140 days. Treatments; $T_{1}, T_{2}, T_{6}$ and $T_{7}$ completed their

Table 3. Phenological parameters of BRRI dhan28 as affected by different treatment combinations.

\begin{tabular}{|c|c|c|c|}
\hline Treatment & Day to 1st & Day to $50 \%$ & Growth duration \\
\hline & flowering & flowering & (day) \\
\hline $\mathrm{T} 1$ & 119 & 122 & 141 \\
\hline $\mathrm{T} 2$ & 120 & 123 & 141 \\
\hline T3 & 119 & 122 & 139 \\
\hline $\mathrm{T} 4$ & 119 & 123 & 140 \\
\hline T5 & 119 & 122 & 139 \\
\hline T6 & 120 & 123 & 141 \\
\hline $\mathrm{T} 7$ & 120 & 123 & 141 \\
\hline $\mathrm{T} 8$ & 120 & 124 & 142 \\
\hline CV (\%) & 0.55 & 0.49 & 0.36 \\
\hline $\operatorname{LSD}(0.05)$ & ns & 1.055 & 0.8964 \\
\hline
\end{tabular}


maturation. Frequent number of MG application may be made delayed in bringing flowering as well as delayed maturity.

Yield and yield components. Filled grain panicle $^{-1}$ and 1000-grain weight (TGW) showed non-significant differences among all the treatment combinations (Table 4). Abdel-Gawad et al. (1989) and Yildirim et al. (2008) also reported that foliar fertilization did not have any statistical effect on TGW. Panicle $\mathrm{m}^{-2}$ recorded significant and observed statistically identical among treatments except $T_{5} . T_{6}$ (362)

Table 4. Yield and yield components of BRRI dhan 28 as influenced by PRH, Calsol and MG.

\begin{tabular}{llllllll}
\hline Treatment & $\begin{array}{l}\text { Panicle } \\
\text { no. m-2 }\end{array}$ & $\begin{array}{l}\text { Filled grain } \\
\text { no. panicle-1 }\end{array}$ & $\begin{array}{l}\text { Unfilled grain } \\
\text { no. panicle-1 }\end{array}$ & $\begin{array}{l}\text { Total grain } \\
\text { no. panicle-1 }\end{array}$ & $\begin{array}{l}\text { Spikelet } \\
\text { fertility (\%) }\end{array}$ & $\begin{array}{l}\text { 1000-grain } \\
\text { wt (gm) }\end{array}$ & $\begin{array}{l}\text { Yield } \\
\text { (tha-1) }\end{array}$ \\
T1 & 344 & 91 & 40 & 131 & 69 & 20.8 & 5.64 \\
T2 & 335 & 86 & 46 & 133 & 65 & 21.2 & 5.35 \\
T3 & 327 & 96 & 48 & 144 & 67 & 20.4 & 5.49 \\
T4 & 351 & 80 & 36 & 117 & 69 & 21.3 & 4.7 \\
T5 & 278 & 90 & 15 & 105 & 86 & 20.9 & 4.05 \\
T6 & 362 & 91 & 58 & 148 & 61 & 21.1 & 5.32 \\
T7 & 331 & 90 & 40 & 130 & 69 & 20.9 & 5.14 \\
T8 & 342 & 82 & 37 & 119 & 69 & 20.4 & 4.53 \\
CV (\%) & 8.31 & 9 & 9.97 & 6.68 & 4.2 & 2.16 & 3.28 \\
LSD $(0.05)$ & 48.6 & ns & 6.984 & 15.01 & 5.097 & ns & 0.2878 \\
\hline
\end{tabular}

However, overall spikelet fertility (\%) recorded maximum in $\mathrm{T}_{5}$ and the remaining treatment showed almost similar trend of spikelet fertility (\%). In terms of grain yield, it responded the highest in $\mathrm{T}_{1}$ represent existing fertilizer practice showing statistically identical with $T_{2}$ and $T_{3}$. Besides, $T_{2}, T_{3}$ and $T_{6}$ had statistically similar yield performance. In $\mathrm{T}_{4}$, half of recommended fertilizer and PRH and $\mathrm{T}_{8}, \mathrm{MG}(59 \% \mathrm{~N} / 129.8 \mathrm{~kg}$ ha $^{-1}$ urea used) response showed similar trend of grain yield production. In $\mathrm{T}_{5}$, where no chemical fertilizer used except PRH produced minimum grain yield among all the treatments. Lin and Zhu (2000) reported that foliar spray of fertilizer at heading stage increased grain yield recorded maximum number of panicle as it had the highest number of tiller $\mathrm{m}^{-2}$. Our findings are compatible to Soylu et al. (2005) and Kenbaev and Sade (2002). They reported that foliar application of different micronutrients individually or in combination significantly increased in number of panicles $\mathrm{m}^{-2}$. On the other hand, the total grain panicle ${ }^{-1}$ found maximum in $T_{6}$. On the other hand, total grain panicle $^{-1}$ was the lowest in $T_{5}$ as well as it had minimum number of unfilled grain panicle ${ }^{-1}$.

Table 5. Partial budget analysis of different fertilizer treatment combination

\begin{tabular}{|c|c|c|c|c|c|c|c|c|}
\hline \multirow[t]{2}{*}{ Total cost and total income } & \multicolumn{8}{|c|}{ Different fertilizer treatment combination } \\
\hline & $\mathrm{T}_{1}$ & $\mathrm{~T}_{1}$ & $\mathrm{~T}_{1}$ & $\mathrm{~T}_{1}$ & $\mathrm{~T}_{1}$ & $\mathbf{T}_{1}$ & $\mathbf{T}_{1}$ & $\mathbf{T}_{1}$ \\
\hline \multicolumn{9}{|c|}{ Cost } \\
\hline \multicolumn{9}{|l|}{ 1. Labor cost } \\
\hline $\begin{array}{l}\text { a. Fertilizer \& other solution weighting and taking to } \\
\text { field (BDT ha-1) }\end{array}$ & 46 & 57 & 57 & 57 & 10 & 53 & 42 & 44 \\
\hline b. Fertilizer \& other solution Application (BDT ha-1) & 2407 & 5915 & 5915 & 5915 & 3508 & 4487 & 3835 & 4610 \\
\hline $\begin{array}{l}\text { 2. Fertilizer \& other solution cost } \\
\left(\text { BDT ha-1) }^{-1}\right.\end{array}$ & 11145 & 28645 & 19895 & 23174 & 17500 & 10935 & 9882 & 10878 \\
\hline Total cost $(\mathrm{Tc})$ & 13598 & 34617 & 25867 & 29146 & 21018 & 15475 & 13759 & 15532 \\
\hline \multicolumn{9}{|c|}{ Income } \\
\hline Economic grain (t ha $\left.{ }^{-1}\right)$ & 5.64 & 5.35 & 5.49 & 4.7 & 4.05 & 5.32 & 5.14 & 4.53 \\
\hline Income (BDT ha-1) & 105750 & 100313 & 102938 & 88125 & 75938 & 99750 & 96375 & 84938 \\
\hline Change in cost $(\Delta \mathrm{C})$ & 0 & 21019 & 12269 & 15548 & 7420 & 1877 & 161 & 1934 \\
\hline Change in income $(\Delta \mathrm{I})$ & 0 & -5438 & -2813 & -17625 & -29813 & -6000 & -9375 & -20813 \\
\hline Marginal Rate of Return, MRR $=(\Delta \mathrm{I} / \Delta \mathrm{C}) * 100$ & 0 & $-26 \%$ & $-23 \%$ & $-113 \%$ & $-402 \%$ & $-320 \%$ & $-5823 \%$ & $-1076 \%$ \\
\hline
\end{tabular}


less than one fourth times a unit of total fertilizer cost. This analysis is done by considering only rice grain yield. If we add the value of the straw, the return will become more than the already estimated income.

\section{CONCLUSIONS}

Maximum grain yield was obtained by existing soil fertilization method and other methods did not demonstrate cost effective economically. The results do not justify the exogenous application of PRH itself and with combined application with soil fertilization method as well as liquid fertilizer Calsol and MG method under conditions where physio-chemical properties of soil are good enough for nutrients uptake from the soil. However, under conditions where nutrients supply to plants become a limiting factor because of soil properties, $\mathrm{PRH}$ and liquid fertilizers can serve as a constructive measure to ensure most advantageous supply of hormone and nutrients to plants. In addition, methods of PRH, Calsol and MG application could be refined upon to obtain uppermost benefit from these products.

\section{REFERENCES}

Abdel, A A, N I Ashour, A O M Saad, A M AboShetta and M K A Ahmed. 1989. The insignificant importance of late nitrogen fertilization on the yield of soybean (Glycine Max L.) in Egypt. Annual and Agriculture Science Ain Shams University, 33: 249-260.

Adam, A M M and G N Jahan. 2011. Effects of Naphthalene Acetic Acid on yield attributes and yield of two varieties of rice (Oryza Sativa L.). Bangladesh J. Bot. 40(1): 97-100.

Arsha, M and J Frankenberger. 1993. Microbial production of plant growth regulators: In: Soil Microbial Echol. FB Metting Jr. (Ed), Marcel Dekker Inc., N Y 307-347.

Bakhsh, I, M Awan, M Sadiq, M Niamatullah, K U Zaman and M Aftab. 2011. Effect of plant growth regulator application at different growth stages on the economical yield potential of coarse rice (Oryza sativa L.) J. Anim. Plant Sci. 21(3):612-616.

BBS (Bangladesh Bureau of Statistics). 2008. Monthly Statistical Bulletin of Bangladesh. Statistics Div., Ministry of Planning, Govt. People's Repub. Bangladesh.

Camberato, J, K Wise and B Johnson. 2010. Glyphosate-manganese interactions and impacts on crop production: the controversy. Purdue University Extension
News and Notes [Online]. http://www.btny.purdue.edu/weedscienc e /2010/GlyphosateMn.pdf

Chowdappa, P, S P M Kumar, M J Lakshmi and K K Upreti. 2013. Growth stimulation and induction of systemic resistance in tomato against early and late blight by Bacillus subtilis OTPB1 or Trichoderma harzianum OTPB3. Biol Control 65: 109-117

Fageria, N K and V C Baligar. 2005. Nutrient availability. In: Encyclopedia of Soils in the Environment, ed. D. Hillel, 63-71.

Gao, Y, A W Duan, X Q Qiu, J S Sun, J P Zhang, H Liu and H Z Wang. 2010. Distribution and use efficiency of photosynthetically active radiation in strip intercropping of maize and soybean. Agron J. 102: 1149-1157.

Jamal, Z, M Hamayun, N Ahmad and M F Chaudhary. 2006. Effect of soil and foliar application of different concentrations of NPK and foliar application of $\left(\mathrm{NH}_{4}\right)_{2} \mathrm{SO}_{4}$ on different parameters in wheat. J. Agron. 5(2): 251-256.

Kenbaev, B and B Sade. 2002. Response of field grown barley cultivars grown on zinc deficient soil to zinc application. Communication in Soil Science and Plant Annual. 33(3-4): 533-544

Khan, W, B Prithiviraj and D L Smith. 2003. Photosynthetic response of corn and soybean to foliar application of salicylates. J. Plant Physiol. 160: 485-492.

Kovacevic, D. 2003. Opšte ratarstvo, Poljoprivredni fakultet, Zemun, 780.

Lin X and D F Zhu. 2000. Effects of regent on growth and yield in rice. Acta. Agric Zhejiangensis. 12: 70-73.

Maclean, J L, D C Dawe, B Hardy and G P Hettel. 2002. Rice Almanac (Third edition). Philippines, IRRI, WARDA, CIAT and FAO.

Michael, A G. 2001. USDA/ARS Children's Nutrition Research Center, Texas, USA Encyclopedia of life sciencces. Nature Publishing Group/www.els.net.

Pingali, P L, M Hossain and R V Gerpacio. 1997. Asian rice market: Demand and supply prospects, Asian rice bowls: The returning drisis? CAB International, Wallingford, UK, and International Rice Research Institute, Los Baños, Philippines. pp 126-144.

Rehm, G W, G Randall and M A Schmitt. 1997. Foliar fertilization of soybeans. Minnesota Crop News 3: 69-70.

Silberbush, L F. 2002. Response of maize to foliar vs soil application of nitrogenphosphorus potassium fertilizers. Journal of Plant Nutr. 25: 2333-2342. 
Soylu, S, B Sade, A Topal, N Akgun and S Gezgin. 2005. Responses of irrigated durum and bread wheat cultivars to boron application in low boron calcareous soil. Turk. J. Agr. 29:275-286.

Talaat, N B. 2003. Physiological studies on the effect of salinity, ascorbic acid and putrescine of sweet paper plant. PhD Thesis, Fac of Agri Cairo Univ. Egypt.

Yildirim, B, N Okut, D Turkozu, O Terzio and M Tuncturk. 2008. The effects of maxicrop leaf fertilizer on the yield and quality of soybean (Glycine max L. Merril). African J. Biotech. 7: 1903-1906. 